\title{
Effectiveness of medical coating materials in decreasing friction between orthodontic brackets and archwires
}

\author{
Nursel Arici ${ }^{\mathrm{a}}(1)$ \\ Berat S. Akdeniz ${ }^{\mathrm{b}}$ \\ Abdullah A. $\mathrm{Oz}^{\mathrm{a}}$ \\ Yucel Gencer ${ }^{c}$ \\ Mehmet Tarakci ${ }^{\mathrm{c}}$ \\ Selim Arici ${ }^{\mathrm{a}}(\mathbb{0})$
}

${ }^{a}$ Department of Orthodontics, Faculty of Dentistry, Ondokuz Mayıs University, Samsun, Turkey

${ }^{\mathrm{b}}$ Department of Orthodontics, Faculty of Dentistry, Kırıkkale University, Kırkkkale, Turkey

'Materials Science and Engineering Department, Engineering Faculty, Gebze Technical University, Kocaeli, Turkey
Objective: The aim of this in vitro study was to evaluate the changes in friction between orthodontic brackets and archwires coated with aluminum oxide $\left(\mathrm{Al}_{2} \mathrm{O}_{3}\right)$, titanium nitride $(\mathrm{TiN})$, or chromium nitride $(\mathrm{CrN})$. In addition, the resistance of the coatings to intraoral conditions was evaluated. Methods: Stainless steel canine brackets, 0.016-inch round nickel-titanium archwires, and $0.019 \times$ 0.025-inch stainless steel archwires were coated with $\mathrm{Al}_{2} \mathrm{O}_{3}$, TiN, and $\mathrm{CrN}$ using radio frequency magnetron sputtering. The coated materials were examined using scanning electron microscopy, an X-ray diffractometer, atomic force microscopy, and surface profilometry. In addition, the samples were subjected to thermal cycling and in vitro brushing tests, and the effects of the simulated intraoral conditions on the coating structure were evaluated. Results: Coating of the metal bracket as well as nickel-titanium archwire with $\mathrm{Al}_{2} \mathrm{O}_{3}$ reduced the coefficients of friction (CoFs) for the bracket-archwire combination $(p<0.01)$. When the bracket and stainless steel archwire were coated with $\mathrm{Al}_{2} \mathrm{O}_{3}$ and TiN, the CoFs were significantly lower (0.207 and 0.372 , respectively) than that recorded when this bracket-archwire combination was left uncoated $(0.552$; $p<0.01)$. The friction, thermal, and brushing tests did not deteriorate the overall quality of the $\mathrm{Al}_{2} \mathrm{O}_{3}$ coatings; however, some small areas of peeling were evident for the TiN coatings, whereas comparatively larger areas of peeling were observed for the $\mathrm{CrN}$ coatings. Conclusions: Our findings suggest that the CoFs for metal bracket-archwire combinations used in orthodontic treatment can be decreased by coating with $\mathrm{Al}_{2} \mathrm{O}_{3}$ and TiN thin films.

[Korean J Orthod 2021;51(4):270-281]

Key words: Thin film coating, Coefficient of friction, Bracket, Archwire

Received October 15, 2020; Revised December 18, 2020; Accepted December 24, 2020.

Corresponding author: Selim Arici.

Professor, Department of Orthodontics, Faculty of Dentistry, Ondokuz Mayıs University, Atakum 55139, Samsun, Turkey.

Tel+90-532-4367923 e-mail sarici@omu.edu.tr

How to cite this article: Arici N, Akdeniz BS, Oz AA, Gencer Y, Tarakci M, Arici S. Effectiveness of medical coating materials in decreasing friction between orthodontic brackets and archwires. Korean J Orthod 2021;51:270-281.

(C) 2021 The Korean Association of Orthodontists.

This is an Open Access article distributed under the terms of the Creative Commons Attribution Non-Commercial License (http://creativecommons.org/licenses/by-nc/4.0) which permits unrestricted non-commercial use, distribution, and reproduction in any medium, provided the original work is properly cited. 


\section{INTRODUCTION}

Controlled mechanical forces are used in orthodontics to create a biologic response to move the teeth. Although several mechanical systems are available, edgewise mechanics, which involve the sliding of brackets or tubes through an archwire, are the most popular. ${ }^{1}$ As observed in all mechanical systems, friction is generated at the point of contact between the bracket and archwire when teeth are moved through the archwire during treatment using sliding mechanics. This friction is caused by the contact between the wire and the surface of the bracket slot, binding between the wire and the corners of the bracket, and notching of the wire as a result of permanent deformation at the wire-bracket corner interface. ${ }^{2}$ Friction can occasionally slow or even stop tooth movement, and orthodontic tooth movement occurs only when the applied forces can adequately overcome the frictional force between the bracket and archwire. ${ }^{3}$ Studies have shown that up to $60 \%$ of the applied force could be lost because of friction during sliding mechanics. ${ }^{4-6}$ For optimal tooth movement and tissue responses, the amount of applied force should be such that it maximizes tooth movement without irreversible side effects. ${ }^{5-7}$

In orthodontic treatment, the friction force is affected by several factors such as the width and depth of the bracket slot, bracket-archwire angulation, shape and size of the archwire, method of ligation, interbracket distance, level of bracket slots between adjacent teeth, forces applied for retraction, and biological variables. ${ }^{8,9}$ The surface characteristics of orthodontic materials also affect the friction force between the bracket and archwire during treatment with fixed appliances. ${ }^{10}$ Different materials with different frictional characteristics, such as stainless steel (SS), gold, chromium-nickel alloy, titanium, polycarbonate, aluminum oxide or alumina $\left(\mathrm{Al}_{2} \mathrm{O}_{3}\right)$, and zirconia, are used to manufacture brackets. ${ }^{11-14}$ However, SS brackets and archwires have been shown to produce the least friction. ${ }^{12,15-17}$ Therefore, metal slots were placed in ceramic brackets to reduce the frictional resistance between the archwire and bracket. ${ }^{12-14}$ Research has accordingly targeted different approaches, including surface treatments and coatings to further reduce friction between the bracket and archwire. ${ }^{18-21}$

Surface treatment techniques such as electrolytic treatment and ion implantation have been used to modify the surfaces of orthodontic metal brackets and archwires. ${ }^{22,23}$ In one study, the surfaces of nickel-titanium (NiTi), beta titanium, and SS wires were modified by a polytetrafluoroethylene (teflon) coating applied using the ion implantation technique. ${ }^{24}$ In other studies testing friction and other mechanical properties, diamond-like carbon films were deposited on NiTi and SS archwires and SS brackets using the plasma-based ion implantation/deposition method. ${ }^{9,20,25}$

Several coating techniques and materials have been used with the objective of improving the surface properties of orthodontic appliances. For instance, a coating technology known as the electrostatic powder technique was used to apply epoxy paint to NiTi wires, and it was found that the coating resulted in reduced friction relative to that without coating. ${ }^{26}$ Another coating technique, physical vapor deposition, was used to coat beta titanium orthodontic archwires with titanium aluminum nitride and tungsten carbide/carbon for the assessment of frictional properties, the surface morphology, and the load deflection rate. ${ }^{18}$ Radio frequency (RF) magnetron sputtering is another technique used for coating orthodontic materials. This technique removes surface atoms from a solid cathode (target) by bombarding it with positive ions from an inert gas discharge; then, it deposits the surface atoms on the surface to form a thin film. ${ }^{27} \mathrm{RF}$ magnetron sputtering is an effective technique because of the inherent versatility, low-temperature thin film deposition, and uniform surface coating. ${ }^{28,29}$ Using this technique, a thin layer of photocatalytic titanium dioxide was applied to SS orthodontic brackets in order to utilize the antiadhesive and antibacterial properties of this compound. ${ }^{30}$ This technique was also used to coat $\mathrm{NiTi}$ orthodontic wires with titanium in order to assess deterioration of the superelasticity of such wires, and it was concluded that this coating method has potential for application in the orthodontic field. ${ }^{31}$

Although some of the surface treatments and coatings described above can decrease the coefficients of friction (CoFs), most had other drawbacks such as low resistance to challenging intraoral conditions, high frictional wear, and delamination or wear of the coating. ${ }^{32}$ Thus far, attempts at improving the mechanical properties of orthodontic archwires using surface treatment and coating techniques have been somewhat satisfactory. However, limited studies have evaluated changes in the frictional properties of brackets and archwires coated with the same material. Therefore, the aim of this in vitro study was to evaluate the changes in friction between SS orthodontic brackets and NiTi and SS archwires coated with $\mathrm{Al}_{2} \mathrm{O}_{3}$, titanium nitride (TiN), or chromium nitride ( $\left.\mathrm{CrN}\right)$. Moreover, the resistance of the coatings in simulated intraoral conditions was evaluated. The null hypothesis was that coating of SS orthodontic brackets and NiTi and SS archwires with $\mathrm{Al}_{2} \mathrm{O}_{3}$, TiN, or $\mathrm{CrN}$ does not affect the in vitro CoFs for the bracket-archwire combination.

\section{MATERIALS AND METHODS}

\section{Materials}

In this in vitro study, $\mathrm{Al}_{2} \mathrm{O}_{3}$, TiN, and $\mathrm{CrN}$ were used 
as coating materials for 50 0.016-inch round, heat-activated NiTi arch wires (3M Unitek, Monrovia, CA, USA), $500.019 \times 0.025$-inch rectangular SS archwires $(3 \mathrm{M}$ Unitek), and 100 upper canine brackets with a slot dimension of 0.022 inches and zero torque and tip values (Victory series, 3M Unitek; Table 1).

\section{Coating procedure}

Samples were coated with a radio frequency/direct current (RF/DC) magnetron sputtering system (Bestec $\mathrm{GmbH}$, Berlin, Germany). This computer-controlled system consists of vacuum units (vacuum chamber, pump, gauges), a sample heating system, sample holders, a sputtering gun, a gas flow system, thickness measurement instruments (instant in situ measurements), and RF/DC power supplies. After surface cleaning, the samples were loaded into the vacuum chamber with the help of sample holders, and the target coating material was placed in front of the material gun. The system was evacuated to a vacuum level of $10^{-8}$ mbar. Then, argon gas with high purity (99.998\%) was input into the system to generate plasma on the surface of the target material.

The surfaces of the brackets and archwires to be coated were etched with argon-RF plasma using an applied power of $100 \mathrm{~W}$ for 10 minutes. Then, a pure titanium (99.95\% purity) mid-layer with an approximate thickness of $60-80 \mathrm{~nm}$ was added to the substrate materials by argon-DC plasma with an applied power of $90 \mathrm{~W}$ for 5 minutes to enhance the adhesion of the coatings. TiN (99.5\% purity) and $\mathrm{Al}_{2} \mathrm{O}_{3}$ (99.99\% purity) discs with a diameter of 3 inches and a thickness of 0.125 inches were used as the target materials, while $\mathrm{CrN}$ coatings were formed by the reactive RF magnetron sputtering method using a disc-shaped $\mathrm{Cr}$ (99.95\% purity) target material in the presence of argon and nitrogen gases (Table 1).

\section{Surface characterization}

The surfaces of the samples were examined using Dektak 8 Profilometer and Nanoscope IV Multimode Atomic Force Microscopy (AFM) (Veeco Metrology Inc., Santa Barbara, CA, USA) before and after the coating process. Sample surfaces were cleaned with ethyl alcohol in an ultrasonic cleaner for 10 minutes before surface profilometry and AFM. Four measurements were made along a line $(400-2,000 \mu \mathrm{m})$ for two samples in each group, and surface roughness values were calculated from the average of these measurements by software supplied with the profilometer.

\section{Intraoral simulation}

Two samples from every coated and uncoated bracket group were subjected to 250 thermal cycles. Thermal cycling was performed in distilled water between $-5^{\circ} \mathrm{C}$ and $+55^{\circ} \mathrm{C}$ with a dwelling time of 30 seconds.

An in vitro toothbrushing test was applied to the coated samples in order to observe the mechanical damage resistance of the coatings after thermal cycling. A testing machine (Figure 1A) composed of a single electric motor, a container, a sample holder, and arms to hold the toothbrush was designed. The electric motor moved a metal arm connected to the toothbrush in an elliptical manner and transformed the elliptical movement into a swinging movement. The samples were placed in a container filled with tap water at room temperature, and tests were carried out using a mediumbristle toothbrush and fluoride toothpaste for 12 hours with a brushing pressure of $40 \mathrm{~g}$. A pea-sized amount $(0.25 \mathrm{~g})$ of the fluoride toothpaste was released on the toothbrush every 15 minutes. After these tests, changes

Table 1. Properties of the bracket, archwires, and coating materials used in this study

\begin{tabular}{|c|c|c|c|}
\hline Material & Code & Properties & Manufacturer \\
\hline Stainless steel bracket (Victory Series) & $\mathrm{B}$ & Slot width $=0.22 "$, Torque $=0^{\circ}$, Angulation $0^{\circ}$ & 3M Unitek ${ }^{\mathrm{TM}}$, USA \\
\hline Nitinol heat-activated arch wire & $\mathrm{NiTi}$ & $0.016 "$ Dia. & 3M Unitek ${ }^{\mathrm{TM}}$, USA \\
\hline $\begin{array}{l}\text { Satinless steel arch wire } \\
\text { (Permachrome Series) }\end{array}$ & SS & Size $=0.019^{\prime \prime} \times 0.025^{\prime \prime}$ & 3M Unitek ${ }^{\mathrm{TM}}, \mathrm{USA}$ \\
\hline Aluminum oxide coating material & $\mathrm{Al}_{2} \mathrm{O}_{3}$ & $\begin{array}{l}\text { Target size }=3.0 " \text { Dia. } \times 0.125 " \text { Thick } \\
\text { Purity }=99.999 \%\end{array}$ & Kurt J Lesker $^{\circledR}$, USA \\
\hline Titanium nitride coating material & $\mathrm{TiN}$ & $\begin{array}{l}\text { Target size }=3.0 " \text { Dia. } \times 0.125 " \text { Thick } \\
\text { Purity }=99.5 \%\end{array}$ & Kurt J Lesker $^{\circledR}$, USA \\
\hline Chromium nitride coating material & $\mathrm{CrN}$ & $\begin{array}{l}\text { Chromium } \\
\text { Target size }=3.00 " \text { Dia. } \times 0.125 " \text { Thick } \\
\text { Purity }=99.95 \% \\
\text { Nitrogen }\left(\mathrm{N}_{2}\right) \text { gas to vacuum chamber }\end{array}$ & Kurt J Lesker ${ }^{\circledR}$, USA \\
\hline
\end{tabular}

B, bracket; NiTi, nickel-titanium; SS, stainless steel; $\mathrm{Al}_{2} \mathrm{O}_{3}$, alumina; TiN, titanium nitride; $\mathrm{CrN}$, chromium nitride; Dia., diameter. 


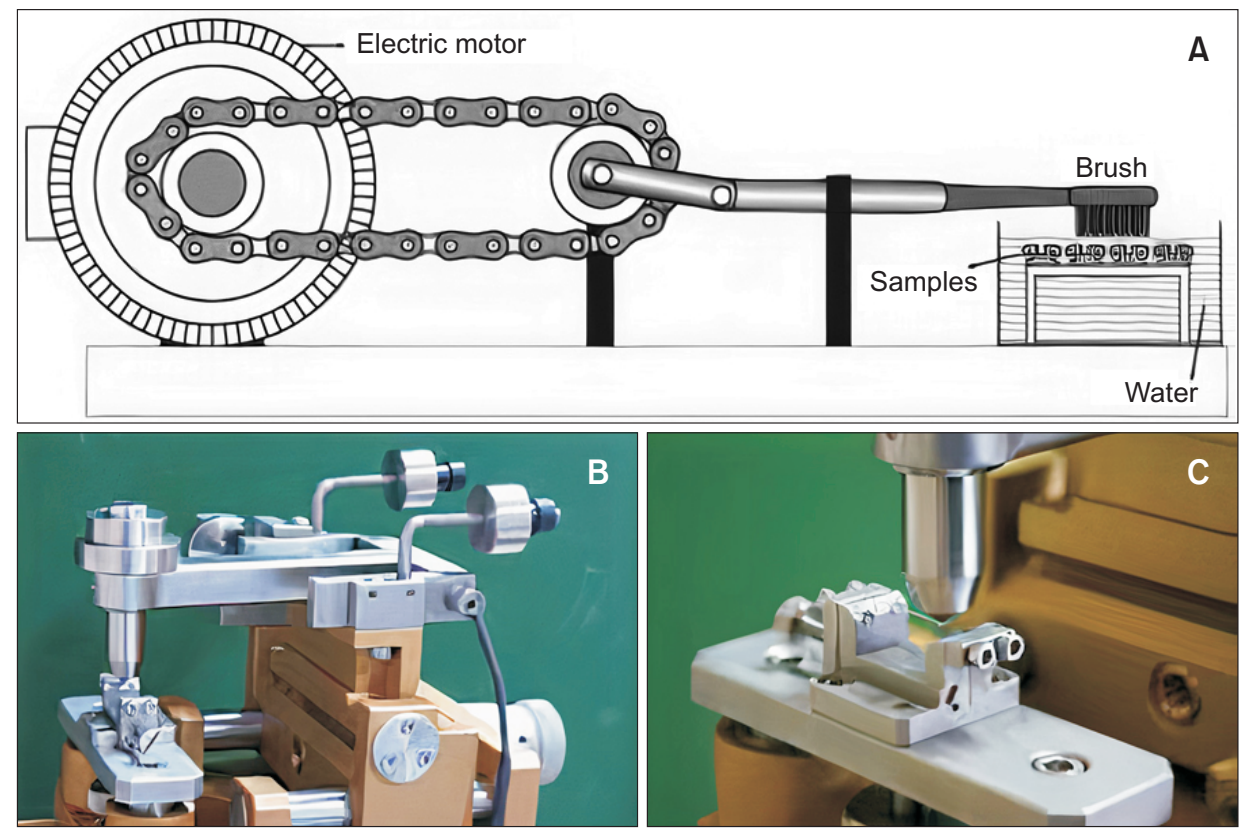

Figure 1. Illustration of the brushing device (A), tribometer (B), and the bracket and archwire holder of the modified tribometer (C) used for evaluating changes in friction between orthodontic brackets and archwires coated with different coating materials. In the brushing test setup (A), the toothbrush moves back and forth linearly on the brackets ligated to a flat archwire. In tribometer, the bracket is attached to a $1 \mathrm{~cm}$ diameter metal ball and rests on the top without moving in a fixed position (B). The bottom plate to which the archwire connected (C) is controlled by a motor that can move at the micron level and a special software. After the archwire is placed in the bracket slot, it moves linearly.

in the surfaces of the materials were investigated.

\section{Friction tests}

CoFs were measured using a modified CSM tribometer (CSM Instruments SA, Peseux, Switzerland; Figure 1B). The sample holder of the tribometer was modified to accommodate the orthodontic materials (Figure 1C). Furthermore, specific software was developed to simulate the slow motion of teeth, calibrate the tribometer, and record and analyze the data. Details regarding the modification and use of the tribometer have been presented in a previous study. ${ }^{12}$

Five samples for every archwire-bracket combination were used for the friction tests. Every bracketarchwire pair was used once, and the friction tests were performed under dry conditions. The samples were cleaned with acetone and dried before the tests. A 150$\mathrm{g}$ load was applied through the vertical axis to simulate the ligation force during sliding mechanics. A standard crosshead speed of $17 \mu \mathrm{m} / \mathrm{s}$ (approximately $1 \mathrm{~mm} / \mathrm{min}$ ) was maintained. The bracket was moved $34 \mathrm{~mm}$ over the archwire during the tests, and approximately 10,000 CoF data points were collected and recorded by the software during each test. The mean value of these data points was used as the mean $\mathrm{CoF}$ for the tested sample. All tests were performed at room temperature $\left(22 \pm 2^{\circ} \mathrm{C}\right)$ and under controlled humidity $(50 \% \pm 10 \%)$. The testing apparatus was enclosed to prevent external effects on the test results.

\section{Scanning electron microscopy (SEM)}

In order to investigate the effects of friction and brushing tests on the coating materials, SEM analysis was performed using the Philips XL30 FEG device (FEl Company, Hillsboro, OR, USA) before and after the coating process. The coating thickness and homogeneity were determined during surface characterization of the coated materials.

\section{Statistical analysis}

In this study, a blind experimental research design was adopted to eliminate the experimental biases that could arise from observers. After the coating procedures, each sample and its group were randomly numbered by a researcher (S.A.) so that the other researchers who performed the thermal cycling, brushing, and friction tests (B.S.A., N.A., and A.A.O.) and the characterization processes (Y.G. and M.T.) were blinded to the group to which the sample belonged. Randomization was performed by computer-generated random codes (Research Randomizer V 4.0). These numbers were kept in a closed envelope until all the tests were completed. 
SPSS 15.0 (SPSS Inc., Chicago, IL, USA) was used for statistical analysis of the $\mathrm{CoF}$ values. The data were examined for normality using the Kolmogorov-Smirnov test. The data for the mean CoF values were normally distributed; thus, one-way analysis of variance (ANOVA) was used for statistical comparison of the data. Statistically significant differences between groups were evaluated using Dunnett's test.

\section{RESULTS}

\section{Reduction in surface roughness}

The surface roughness measurements obtained before and after coating of the brackets and archwires are shown in Table 2. Surface roughness decreased with the coating process in all groups, with the greatest reduction (almost 60\%) observed for the SS archwires with the $\mathrm{Al}_{2} \mathrm{O}_{3}$ coating. The lowest surface roughness values were obtained for the brackets and NiTi archwires coated with $\mathrm{CrN}(\mathrm{Ra}=276.85 \mathrm{~nm}$ and $\mathrm{Ra}=354.35 \mathrm{~nm}$, respectively).

As shown in Figure 2, the roughest surface was observed for the uncoated NiTi archwire $(\mathrm{Ra}=439.34$ $\mathrm{nm}$ ), and all three coatings resulted in significant reductions in the surface roughness of this wire. In contrast, the uncoated SS archwire exhibited a very low surface roughness value $(\mathrm{Ra}=234.44 \mathrm{~nm})$.

The SEM and AFM images of the coated and uncoated archwires clearly showed a reduction in surface roughness after the coating process (Figure 2). Moreover, SEM, AFM, and surface profilometry showed that the coated brackets had homogenous and smooth surfaces. The pits and irregularities on the bracket edges were filled with coating materials (Figure 3). Measurements from different regions of the bracket and slot base showed that the coating had a homogeneous distribution, with an average film thickness of $5,600 \AA(0.56 \pm 0.03 \mu \mathrm{m})$.

\section{Reduction in coefficients of friction}

The results of the friction tests were grouped according to the archwire material. Table 3 shows the descriptive statistics and differences between the coated and uncoated metal brackets and archwires. The values are also graphically presented in Figure 4.

The mean CoF for the uncoated bracket and $\mathrm{NiTi}$ archwire combination was 0.316. The lowest $\mathrm{CoF}$ was identified for the $\mathrm{Al}_{2} \mathrm{O}_{3}$-coated bracket and $\mathrm{Al}_{2} \mathrm{O}_{3}$-coated NiTi archwire combination ( $\mathrm{CoF}$ 0.238), followed by the $\mathrm{Al}_{2} \mathrm{O}_{3}$-coated bracket and uncoated NiTi archwire combination (CoF 0.251). The decreases in friction in these two groups were statistically significant $(p<0.05$; Table 3).

Table 3 also shows the mean CoF values and statistical differences between the coated and uncoated brackets and SS archwires. The CoF for the control group was 0.552. The $\mathrm{Al}_{2} \mathrm{O}_{3}$-coated bracket and SS archwire combination showed a significant decrease in friction $(p<$ 0.05), with the lowest mean $\mathrm{CoF}(0.207)$. There was a significant decrease in friction ( $\mathrm{CoF}$ 0.237) between the TiN-coated bracket and uncoated SS archwire. However, the CoF (0.818) for the uncoated bracket and TiN-

Table 2. Surface roughness parameters for uncoated and coated brackets and nickel-titanium (NiTi) and stainless steel archwires

\begin{tabular}{|c|c|c|c|c|c|}
\hline \multirow[b]{2}{*}{ Brackets and arch wires } & \multirow[b]{2}{*}{$\begin{array}{l}\text { Coating } \\
\text { material }\end{array}$} & \multirow[b]{2}{*}{$\underset{(\mu \mathrm{m})}{\text { Measuring range }}$} & \multicolumn{3}{|c|}{ Roughness parameters } \\
\hline & & & $\begin{array}{c}\text { Arithmetic } \\
\text { average } \\
\text { roughness (Ra) } \\
(\mathrm{nm})\end{array}$ & $\begin{array}{c}\text { Root mean } \\
\text { square } \\
\text { roughness }(\mathrm{Rq}) \\
(\mathrm{nm})\end{array}$ & $\begin{array}{l}\text { Total height of } \\
\text { profile (Rt) } \\
(\mu \mathrm{m})\end{array}$ \\
\hline \multirow[t]{4}{*}{ Bracket slot base } & Uncoated & $250 \times 250$ & 459.17 & 564.85 & 3.82 \\
\hline & $\mathrm{Al}_{2} \mathrm{O}_{3}$ & $250 \times 250$ & 331.53 & 426.17 & 3.93 \\
\hline & $\mathrm{TiN}$ & $250 \times 250$ & 354.12 & 458.74 & 4.22 \\
\hline & $\mathrm{CrN}$ & $250 \times 250$ & 276.85 & 360.34 & 2.94 \\
\hline \multirow{4}{*}{$\begin{array}{l}\text { Heat-activated NiTi arch wire } \\
\text { (0.016-inch round) }\end{array}$} & Uncoated & $250 \times 500$ & 439.34 & 564.88 & 5.74 \\
\hline & $\mathrm{Al}_{2} \mathrm{O}_{3}$ & $250 \times 500$ & 361.64 & 466.01 & 3.78 \\
\hline & $\mathrm{TiN}$ & $250 \times 500$ & 391.99 & 534.36 & 6.66 \\
\hline & $\mathrm{CrN}$ & $250 \times 500$ & 354.35 & 454.66 & 6.21 \\
\hline \multirow{4}{*}{$\begin{array}{l}\text { Stainless steel arch wire } \\
(0.019 \times 0.025 \text {-inch rectangular })\end{array}$} & Uncoated & $250 \times 500$ & 234.44 & 268.25 & 2.13 \\
\hline & $\mathrm{Al}_{2} \mathrm{O}_{3}$ & $250 \times 500$ & 95.86 & 128.01 & 1.74 \\
\hline & $\mathrm{TiN}$ & $250 \times 500$ & 105.15 & 132.67 & 1.25 \\
\hline & $\mathrm{CrN}$ & $250 \times 500$ & 190.28 & 229.26 & 1.51 \\
\hline
\end{tabular}

$\mathrm{Al}_{2} \mathrm{O}_{3}$, alumina; TiN, titanium nitride; $\mathrm{CrN}$, chromium nitride. 

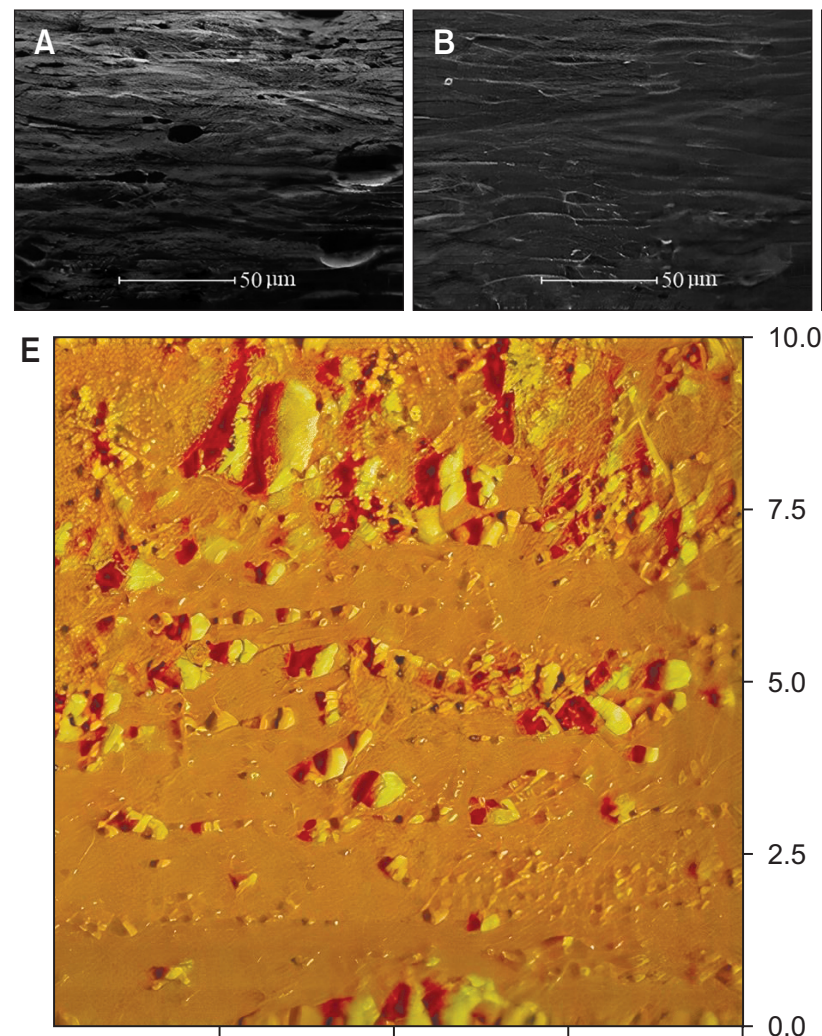

2.5

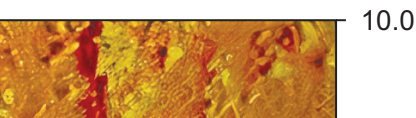

,
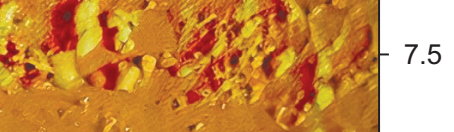

\section{.5}

$-2.5$

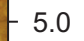

$\mathrm{F}$
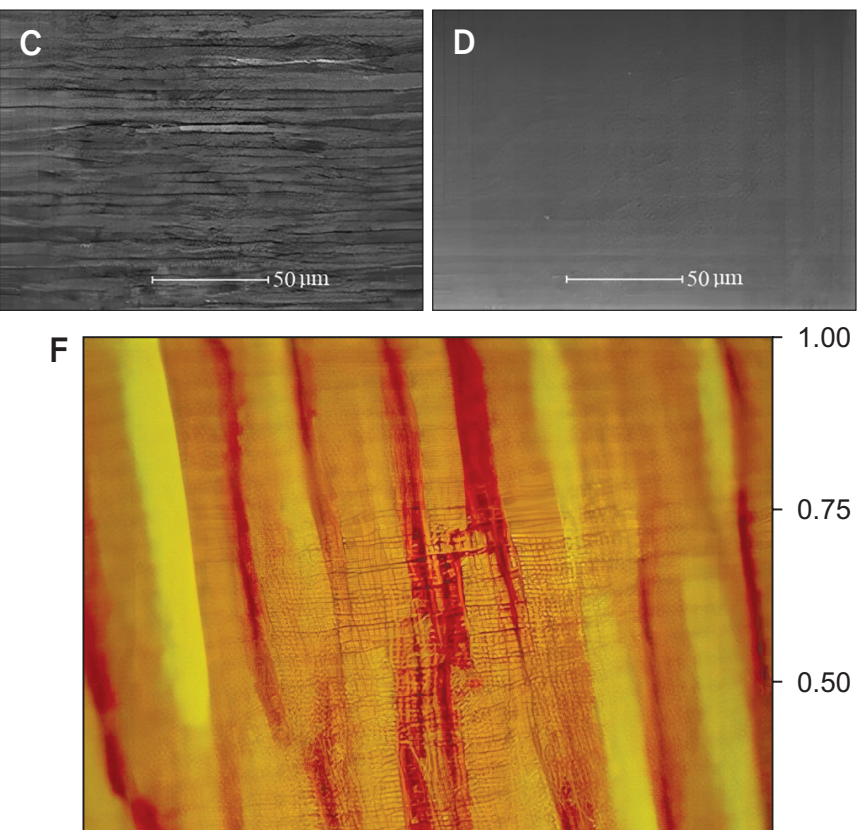

Figure 2. Scanning electron microscopy (SEM) images and atomic force microscopy (AFM) of nickel-titanium (NiTi) and stainless steel (SS) archwires. The SEM images of the uncoated NiTi (A), titanium nitride-coated NiTi (B), uncoated SS (C), and chromium nitride (CrN)-coated SS (D) clearly show that there is an increase in smoothness on their surfaces after the coating process. The AFM images show that the surface roughness of the uncoated SS archwire surface (E) decreased with the $\mathrm{CrN}$ coating (F).

coated SS archwire combination was the highest among all groups. The CrN coating, on the other hand, was ineffective in decreasing friction; the mean CoF for nearly all the bracket-archwire pairs showed an increase. Remarkably, an increase in CoFs was observed in almost all scenarios involving a combination of a coated NiTi or SS archwire and an uncoated bracket (Figure 4).

\section{Coating resistance to physical tests}

Wear associated with the friction tests was apparent in the SEM images of all uncoated and coated samples. The friction, thermal, and brushing tests did not affect the overall quality of the $\mathrm{Al}_{2} \mathrm{O}_{3}$ coatings; however, peeling of TiN was observed in some small areas (Figures 5 and 6). The $\mathrm{CrN}$ coating showed the poorest results in all tests. Large areas of peeling could be seen on the bracket surfaces, and there was significant material transfer between the bracket base and archwire as a result of frictional wear (Figures 5G, 5H, and 6D).

\section{DISCUSSION}

In the present study, we evaluated the effectiveness of TiN, $\mathrm{Al}_{2} \mathrm{O}_{3}$, and $\mathrm{CrN}$ coatings in decreasing friction between orthodontic brackets and archwires. The results revealed that the TiN and $\mathrm{Al}_{2} \mathrm{O}_{3}$ coatings could successfully decrease the CoFs.

Initially, $\mathrm{Al}_{2} \mathrm{O}_{3}$, TiN, silicon carbide ( $\mathrm{SiC}$ ), and $\mathrm{CrN}$, which are biocompatible and used for coating medical instruments and implants, were selected as coating materials for this study. ${ }^{33-36}$ Single-crystal silicon with an orientation of (100), glass, and AISI 316L SS surfaces were coated with these four target materials using the RF/DC magnetron sputtering system under different experimental conditions. The goal was to determine the formability of the coating materials, optimize the coating conditions, and obtain the necessary reference information. After the pilot study, the coated surfaces were characterized by performing SEM and X-ray diffraction. Furthermore, a 20-h brushing test was performed to evaluate the resistance of the coating against mechani- 

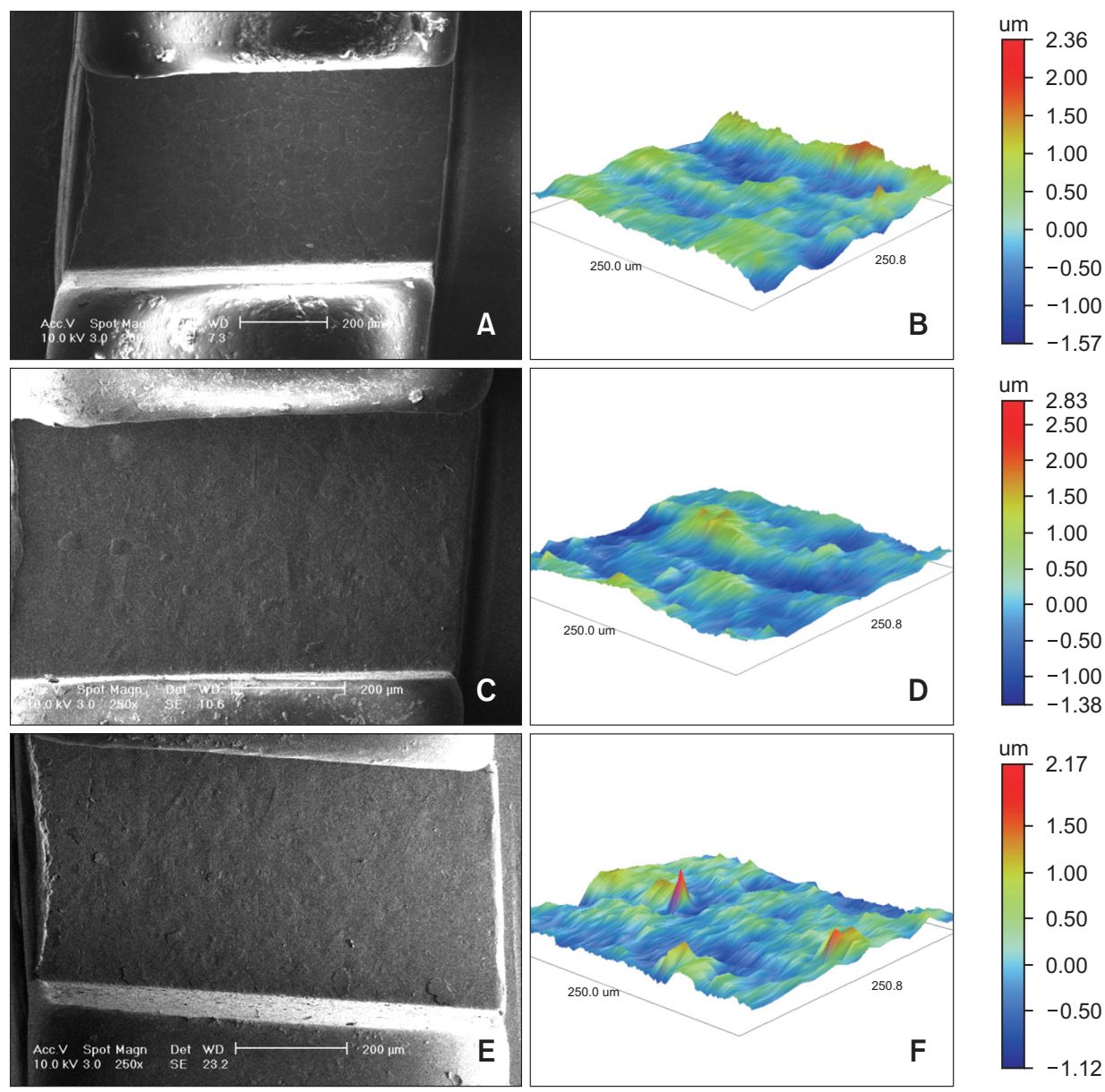

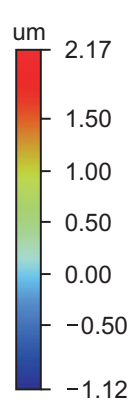

Figure 3. Scanning electron microscopy (SEM) images and surface profilometry results for alumina $\left(\mathrm{Al}_{2} \mathrm{O}_{3}\right)$-coated (A, B), titanium nitride (TiN)coated $(\mathbf{C}, \mathbf{D})$, and chromium nitride $(\mathrm{CrN})$-coated $(\mathrm{E}, \mathrm{F})$ bracket slots. The pits and irregularities on the bracket edges were filled with coating materials as shown in the SEM images $(A, C, E)$ and profilometer images $(\mathbf{B}, \mathbf{D}, \mathbf{F})$ of coated btacket slots with $\mathrm{Al}_{2} \mathrm{O}_{3}(\mathbf{A}, \mathbf{B}), \operatorname{TiN}(\mathbf{C}, \mathbf{D})$, and $\mathrm{CrN}(\mathrm{E}, \mathrm{F})$.

Table 3. Comparisons of coefficients of friction among different combinations of coated and uncoated brackets and nickel-titanium (NiTi) and stainless steel (SS) archwires

\begin{tabular}{ccccccc}
\hline Bracket (B) \& arch wire (NiTi, SS) combination & Sample & \multirow{2}{*}{ Control } & \multicolumn{3}{c}{ Coating material } \\
\cline { 5 - 6 } Uncoated & Coated & size & & $\mathbf{A l}_{2} \mathbf{O}_{3}$ & TiN & CrN \\
\hline B-NiTi & & 5 & $0.316 \pm 0.029^{\mathrm{A}}$ & & & \\
& $\mathrm{B}-\mathrm{NiTi}$ & 5 & & $0.238 \pm 0.017^{\mathrm{B}}$ & $0.399 \pm 0.055^{\mathrm{A}}$ & $0.443 \pm 0.058^{\mathrm{C}}$ \\
B & $\mathrm{NiTi}$ & 5 & & $0.400 \pm 0.037^{\mathrm{C}}$ & $0.446 \pm 0.013^{\mathrm{C}}$ & $0.505 \pm 0.075^{\mathrm{C}}$ \\
$\mathrm{NiTi}$ & $\mathrm{B}$ & 5 & & $0.251 \pm 0.021^{\mathrm{B}}$ & $0.331 \pm 0.059^{\mathrm{A}}$ & $0.324 \pm 0.080^{\mathrm{A}}$ \\
B-SS & 5 & $0.552 \pm 0.074^{\mathrm{D}}$ & & \\
& & 5 & & $0.207 \pm 0.034^{\mathrm{E}}$ & $0.372 \pm 0.050 \mathrm{E}^{\mathrm{F}}$ & $0.598 \pm 0.168^{\mathrm{D}}$ \\
B & $\mathrm{B}-\mathrm{SS}$ & 5 & & $0.445 \pm 0.169^{\mathrm{D}}$ & $0.818 \pm 0.420^{\mathrm{D}}$ & $0.586 \pm 0.142^{\mathrm{D}}$ \\
SS & SS & 5 & & $0.235 \pm 0.072^{\mathrm{E}}$ & $0.237 \pm 0.066^{\mathrm{E}}$ & $0.410 \pm 0.244^{\mathrm{D}}$ \\
\hline
\end{tabular}

Values are presented as mean \pm standard deviation.

Different letters indicate statistically significant $(p<0.05)$ differences between the subgroups within the group containing the same archwire and bracket combination (B-NiTi and B-SS).

$\mathrm{Al}_{2} \mathrm{O}_{3}$, alumina; TiN, titanium nitride; $\mathrm{CrN}$, chromium nitride.

cal factors. In the SEM examinations, it was observed that $\mathrm{TiN}, \mathrm{Al}_{2} \mathrm{O}_{3}$, and $\mathrm{CrN}$ formed a homogenous coating on SS, without any major adhesion problems. However,
SiC did not adhere well to the SS plate. Because this adhesion problem was commonly observed on the surfaces of the samples, the SiC coating was excluded from this 


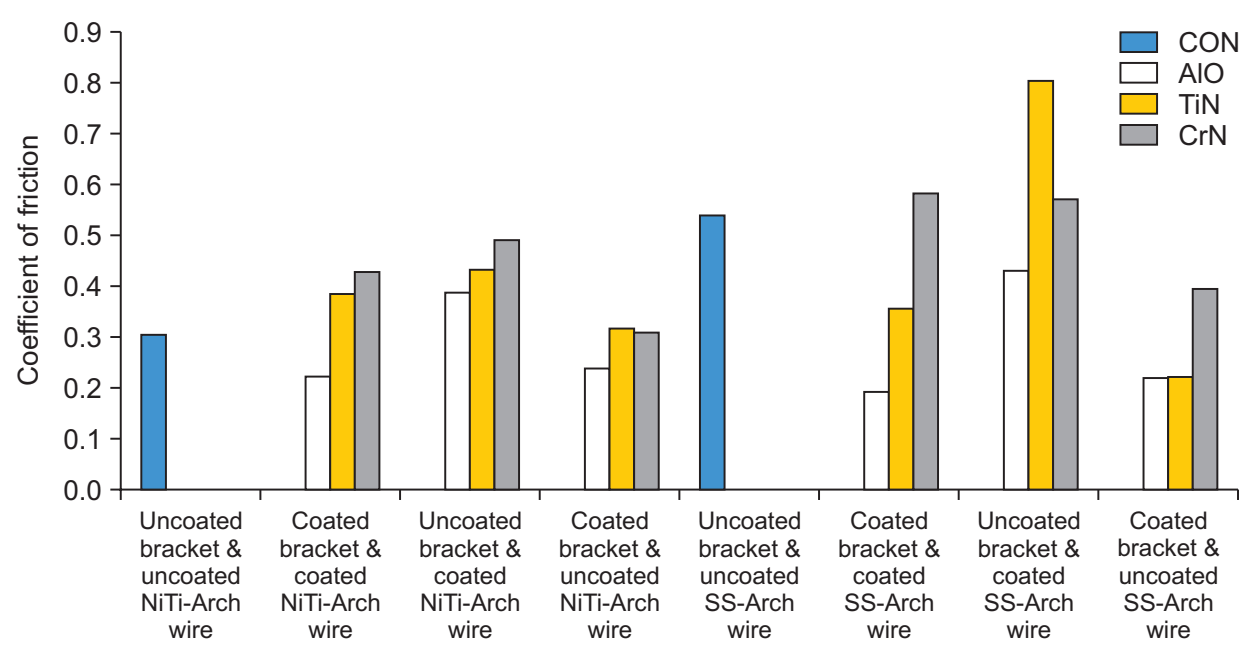

Figure 4. Graphical representation of the coefficients of friction (CoFs) for uncoated (CON), alumina $\left(\mathrm{Al}_{2} \mathrm{O}_{3}\right)$-coated $(\mathrm{AIO})$, titanium nitride (TiN)-coated, and chromium nitride ( $\mathrm{CrN}$ )-coated bracket and nickel-titanium (NiTi) and stainless steel (SS) archwire combinations. Among all groups, the lowest mean CoF value was observed in the AIO coated bracket / AIO coated SS archwire group, whereas the highest mean CoF value was observed in the uncoated bracket / TiN coated SS archwire group.
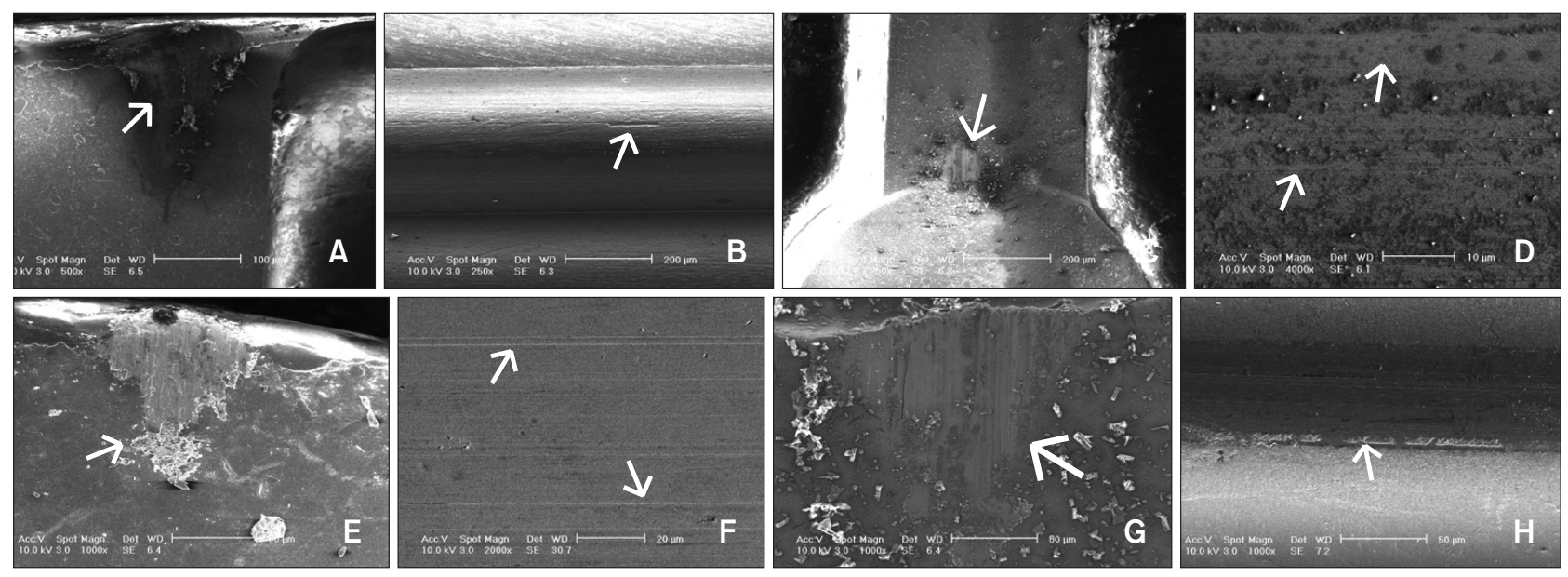

Figure 5. Scanning electron microscopy images show the frictional wear patterns for uncoated bracket and nickel-titanium (NiTi) archwire $(A, B)$, alumina $\left(\mathrm{Al}_{2} \mathrm{O}_{3}\right)$-coated bracket and uncoated stainless steel archwire $(\mathbf{C}, \mathbf{D})$, titanium nitride (TiN)-coated bracket and uncoated stainless steel archwire ( $\left.E_{1}, \mathbf{F}\right)$, and chromium nitride (CrN)-coated bracket and CrNcoated NiTi archwire $(\mathbf{G}, \mathbf{H})$ pairs. The arrows indicate areas of heavy wear that occurred on the coatings and underlying materials during friction tests.

study.

Various coatings are used on orthodontic attachments, mostly for esthetic reasons. Teflon coatings are used to change the natural dark color of NiTi archwires to a lighter color. Such wires are primarily used with esthetic brackets. A teflon coating is known to have a relatively low $\mathrm{CoF}$, and some studies have shown that it decreases the frictional resistance between brackets and archwires $;^{19}$ however, any mechanical disturbance can easily cause the coating to peel off from the surface.
The peeled coating materials then cause mechanical locking between the archwire and bracket, which in turn increases the $\mathrm{CoF}^{24}$

Coatings with better mechanical properties and low CoFs have recently been introduced, and some are already in clinical use. TiN is one such material. 1ts greatest advantage for clinical use is its accreditation by the US Food and Drug Administration. TiN coatings have been used to achieve improved performance of surgical instruments and implants, and they provide an inert 

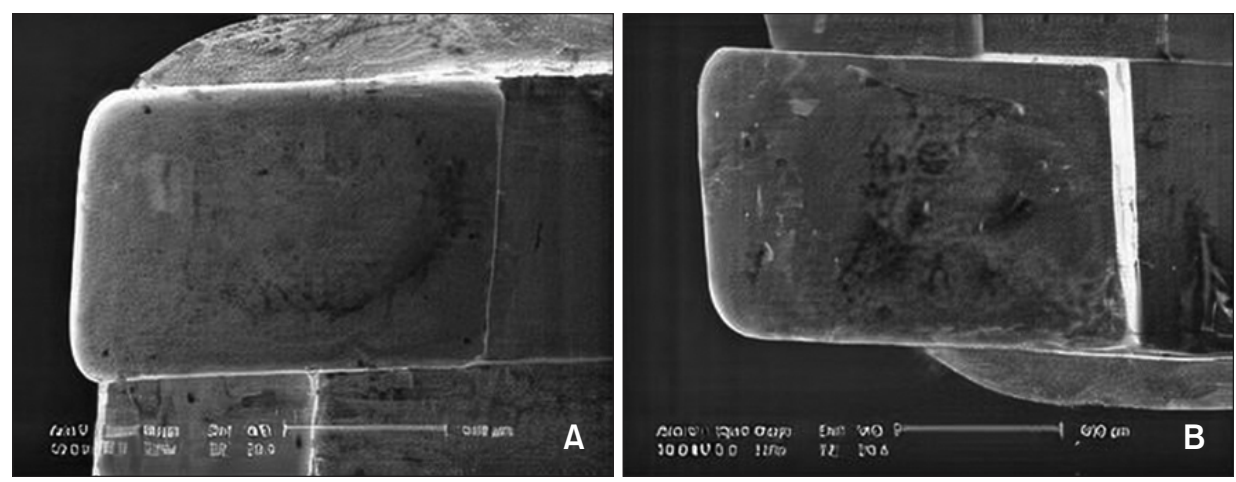

Figure 6. Scanning electron microscopy images of uncoated $(\mathrm{A})$, alumina $\left(\mathrm{Al}_{2} \mathrm{O}_{3}\right)$ coated (B), titanium nitride (TiN)-coated (C), and chromium nitride $(\mathrm{CrN})$-coated (D) bracket samples after brushing and thermal cycling
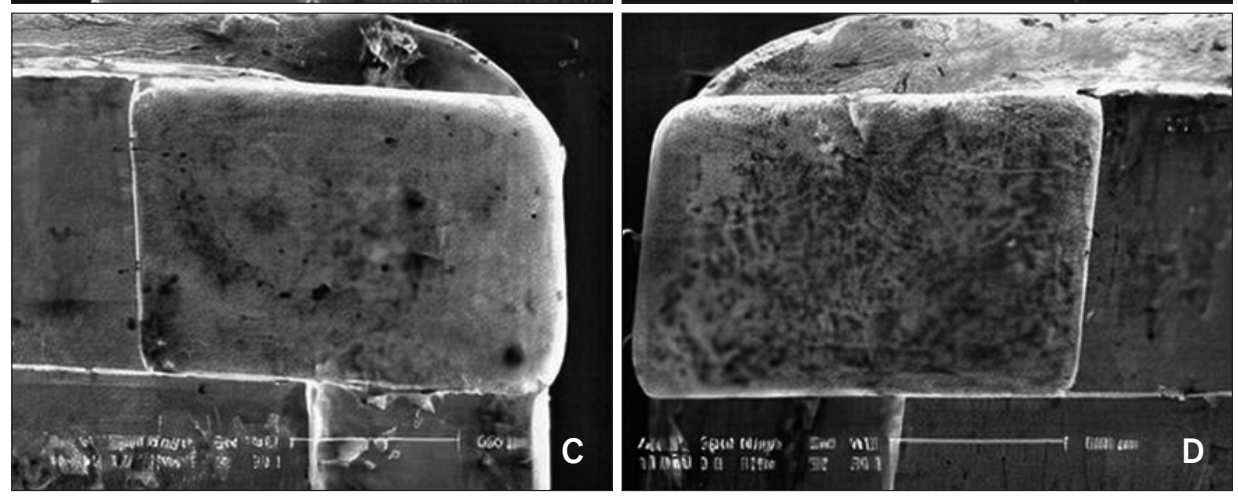
tests. In areas where toothbrush contact is very high, such as the outer surfaces of the bracket wings, it appears that the $\mathrm{Al}_{2} \mathrm{O}_{3}$ coating (B) was not affected much by brushing and thermal cycling tests, but the TiN coating (C) was slightly affected and the $\mathrm{CrN}$ coating (D) was very much affected.

barrier that protects the surface from corrosion and increases wear resistance. ${ }^{34,35,37}$ Additionally, it has been shown that TiN coatings can reduce the adverse effects of nickel allergies and decrease the friction caused by NiTi wires. ${ }^{38}$ Kao et al. ${ }^{39}$ asserted that TiN coatings were useful for decreasing surface roughness, but unlike the present study, their study found that a TiN coating had no effect on the CoF. Although they used a similar but slightly thicker titanium mid-layer under the coating on SS brackets as well as uncoated SS wires, the other coating conditions and friction measurement techniques were different from those used in the present study. Our results showed that a TiN coating on orthodontic brackets could decrease the CoF by almost $50 \%$ if SS archwires were used. Our results, and those of previous studies, show that the coating technique and conditions play an important role in determining the frictional characteristics of the end product, and that TiN coatings can be beneficial in orthodontic applications, particularly for decreasing surface roughness and friction.

$\mathrm{Al}_{2} \mathrm{O}_{3}$ has been used as a coating material in the medical field because of its high corrosion resistance. ${ }^{40}$ Liu et $\mathrm{al}^{41}$ tested the corrosion resistance and frictional properties of biomedical NiTi plates coated using a micro-arc oxidation technique involving an electrolyte-containing sodium aluminate solution. They claimed that $\mathrm{Al}_{2} \mathrm{O}_{3}$ was synthesized on the surface of NiTi. Although they reported a significant increase in surface roughness, they also reported improved frictional behavior and a decrease in corrosion resistance. The results of our study align with those of Liu et al. ${ }^{41}$ in terms of frictional properties, although the $\mathrm{Al}_{2} \mathrm{O}_{3}$ layer in our study was very smooth, and its surface roughness and frictional properties were much better than those reported by liu et al. ${ }^{41}$

$\mathrm{CrN}$ coatings were previously used on SS instruments. They enhanced the surface properties of tool steels, considering $\mathrm{CrN}$ provides good wear resistance and enhanced resistance to corrosion..$^{42}$ Although the $\mathrm{CrN}$ coating showed the lowest surface roughness values, it increased the CoF in the present study. SEM images obtained after the friction tests showed that the coating peeled off from the surface; thus, the residual coating material at the contact point between the surfaces could be the reason for the increased CoF. Although the same problem was observed for the TiN coating, the peeling was not as severe as that observed for the CrN coating, and it did not seem to affect the CoF as much as the peeling of the $\mathrm{CrN}$ coating. This problem with $\mathrm{TiN}$ and $\mathrm{CrN}$ coatings can be attributed to thermal expansion differences between the base material and coating materials.

An important fact to consider is that there is no standardization in terms of test setups among previously published studies evaluating friction between the bracket and archwire in orthodontics. The diversity of results obtained is based on the differences among experimental setups and systems created, the force application points, and the angles formed between the bracket and 
archwire. $^{43}$ Of course, scientifically important information is obtained from every study. However, because of the abovementioned factors, it becomes impossible to make comparisons between the results of different studies. Testing the same bracket and archwire in different setups could result in the acquisition of data with several differences. Moreover, the existence of several brackets and archwires of different types and brands in the market, and the feasibility to perform friction tests with thousands of different bracket/archwire combinations, further complicate such comparisons, which become even more difficult when friction tests are performed with archwires and/or brackets coated with different materials and techniques. Thus, comparisons among the numerical values obtained in the present study and those obtained in other studies involving friction tests for coated brackets and/or archwires were avoided.

In the present study, two different archwire materials were used to evaluate the effects of the coatings during different phases of orthodontic treatment. Round, heatactivated $\mathrm{NiTi}$ archwires were selected because they are used during the leveling phase of orthodontic treatment, while rectangular SS wires were selected because they are used for space closure.

The purpose of performing the thermal cycling test in the present study was to simulate accelerated aging by thermally induced stresses similar to those observed when the coated brackets and archwires would be exposed to moisture and thermal changes in the oral environment. This thermal cycling test is mainly used for testing the bond strength of adhesives, and there is no standardization in terms of the number of thermal cycles among different studies. Although the number of cycles vary between 100 and 20,000, 250 cycles were used in the present study because the heat exchange level in each thermal cycle are very low $\left(-5^{\circ} \mathrm{C}\right.$ to $\left.+55^{\circ} \mathrm{C}\right)$, and it was thought that this would not have a significant effect on the coatings. Our aim was to check whether thermal stresses delaminated the coatings from the surfaces, and this effect could be observed even with just a few thermal cycles.

The effects of abrasive dentifrices on coated brackets and archwires were evaluated by conducting a brushing test in the present study, and adverse effects were observed. A 12-h brushing test was performed using a specially designed device; this duration corresponds to approximately 1 year of toothbrushing based on the amount of time that the brush will act on a group of teeth during an average daily brushing session. ${ }^{44}$ Changes in the surface morphology were investigated, especially with close magnification of the outer surfaces of the bracket wings that came in contact with the toothbrush. Changes in areas where there was no toothbrush contact were attributed to the precipitation of ions from the toothpaste and tap water during the thermal cycling and brushing tests.

The results of clinical studies on the frictional properties of mechanical systems used for orthodontic treatment can be easily affected by various factors in the oral environment and personal differences between patients. On the other hand, in vitro studies use a standard testing environment and larger sample size. Thus, in vitro friction tests were performed in this study to minimize environmental effects and determine the effect of the coating on friction between the bracket and archwire. These tests were performed in a dry environment. Previous studies regarding the role of natural or synthetic saliva during orthodontic friction tests have reported mixed results; some reported that artificial saliva increased friction, ${ }^{45,46}$ while others claimed that wet conditions have no effect on the frictional properties of various materials. ${ }^{47,48}$

The results of the present study and previous studies indicate that the coating technique and conditions are the most important factors determining the physical properties of material surfaces. More studies are needed to determine the optimum coating material and technique. Future studies should also focus on the effect of the same coating techniques on the CoFs of titanium orthodontic brackets, which are known to produce relatively high friction and surface roughness.

An important limitation of this study is that the changes in the coated surfaces of archwires and brackets after the thermal cycling, brushing, and friction tests were primarily examined under a scanning electron microscope, which provides only qualitative results. However, we believe that sufficient data about the condition of the coatings can be obtained with the use of not only constant parameters but also different experimental variables at each step (after and before thermal cycling, brushing, and friction tests for each bracket-archwire pair [those with and without coating and those supplied by different companies]).

As stated before, the aim of this in vitro study was to investigate combinations of surface coatings considered suitable for reducing friction between orthodontic brackets and archwires. However, it should be kept in mind that a low CoF value for a bracket-archwire pair is not always desirable for all patients and all clinical applications. At the same time, clinicians should consider individual patient requirements, such as the type of treatment mechanics, need for anchorage, type of tooth movement, mechanics used for space closure, and amount of space, when selecting the ideal bracket-archwire combination. 


\section{CONCLUSION}

- $\mathrm{Al}_{2} \mathrm{O}_{3}$, TiN, and $\mathrm{CrN}$ coatings were successfully applied by the RF/DC magnetron sputtering system.

- Microstructural characterization revealed that the $\mathrm{Al}_{2} \mathrm{O}_{3}$ and TiN coatings were resistant to intraoral conditions and could not be peeled off easily.

- The CoF for metal brackets combined with round $\mathrm{NiTi}$ or rectangular SS archwires could be decreased by coating with $\mathrm{Al}_{2} \mathrm{O}_{3}$ and $\mathrm{TiN}$, but not by coating with CrN.

\section{CONFLICTS OF INTEREST}

No potential conflict of interest relevant to this article was reported.

\section{ACKNOWLEDGEMENTS}

The authors would like to thank The Scientific and Technological Research Council of Turkey for the support provided for this research (Project No: 105S055).

\section{REFERENCES}

1. Frank CA, Nikolai RJ. A comparative study of frictional resistances between orthodontic bracket and arch wire. Am J Orthod 1980;78:593-609.

2. Kusy RP, Whitley JQ. Influence of archwire and bracket dimensions on sliding mechanics: derivations and determinations of the critical contact angles for binding. Eur J Orthod 1999;21:199-208.

3. Wichelhaus A, Geserick M, Hibst R, Sander FG. The effect of surface treatment and clinical use on friction in NiTi orthodontic wires. Dent Mater 2005; 21:938-45.

4. Kojima Y, Fukui H. Numerical simulation of canine retraction by sliding mechanics. Am J Orthod Dentofacial Orthop 2005;127:542-51.

5. Pilon JJ, Kuijpers-Jagtman AM, Maltha JC. Magnitude of orthodontic forces and rate of bodily tooth movement. An experimental study. Am J Orthod Dentofacial Orthop 1996;110:16-23.

6. Nikolai RJ. On optimum orthodontic force theory as applied to canine retraction. Am J Orthod 1975; 68:290-302.

7. Burrow SJ. Friction and resistance to sliding in orthodontics: a critical review. Am J Orthod Dentofacial Orthop 2009;135:442-7.

8. Mendes K, Rossouw PE. Friction: validation of manufacturer's claim. Semin Orthod 2003;9:236-50.

9. Muguruma T, lijima M, Brantley WA, Mizoguchi 1. Effects of a diamond-like carbon coating on the frictional properties of orthodontic wires. Angle Or- thod $2011 ; 81: 141-8$.

10. Kusy RP, Whitley JQ. Friction between different wire-bracket configurations and materials. Semin Orthod 1997;3:166-77.

11. Kapur R, Sinha PK, Nanda RS. Comparison of frictional resistance in titanium and stainless steel brackets. Am J Orthod Dentofacial Orthop 1999;116: 271-4.

12. Arici N, Akdeniz BS, Arici S. Comparison of the frictional characteristics of aesthetic orthodontic brackets measured using a modified in vitro technique. Korean J Orthod 2015;45:29-37.

13. Loftus BP, Artun J, Nicholls Jl, Alonzo TA, Stoner JA. Evaluation of friction during sliding tooth movement in various bracket-arch wire combinations. Am J Orthod Dentofacial Orthop 1999;116:336-45.

14. Russell JS. Current products and practice: aesthetic orthodontic brackets. J Orthod 2005;32:146-63.

15. Doshi UH, Bhad-Patil WA. Static frictional force and surface roughness of various bracket and wire combinations. Am J Orthod Dentofacial Orthop 2011; 139:74-9.

16. Cacciafesta V, Sfondrini MF, Ricciardi A, Scribante A, Klersy C, Auricchio F. Evaluation of friction of stainless steel and esthetic self-ligating brackets in various bracket-archwire combinations. Am J Orthod Dentofacial Orthop 2003;124:395-402.

17. Alfonso MV, Espinar E, Llamas JM, Rupérez E, Manero JM, Barrera JM, et al. Friction coefficients and wear rates of different orthodontic archwires in artificial saliva. J Mater Sci Mater Med 2013;24: 1327-32.

18. Krishnan V, Ravikumar KK, Sukumaran K, Kumar $\mathrm{KJ}$. In vitro evaluation of physical vapor deposition coated beta titanium orthodontic archwires. Angle Orthod 2012;82:22-9.

19. Farronato G, Maijer R, Carì MP, Esposito L, Alberzoni D, Cacciatore G. The effect of Teflon coating on the resistance to sliding of orthodontic archwires. Eur J Orthod 2012;34:410-7.

20. Kang T, Huang SY, Huang JJ, Li QH, Diao DF, Duan YZ. The effects of diamond-like carbon films on fretting wear behavior of orthodontic archwirebracket contacts. J Nanosci Nanotechnol 2015;15: 4641-7.

21. Zuo J, Xie Y, Zhang J, Wei Q, Zhou B, Luo J, et al. TiN coated stainless steel bracket: tribological, corrosion resistance, biocompatibility and mechanical performance. Surf Coat Technol 2015;277:227-33.

22. Horiuchi Y, Horiuchi M, Hanawa T, Soma K. Effect of surface modification on the photocatalysis of Ti$\mathrm{Ni}$ alloy in orthodontics. Dent Mater J 2007;26:9249.

23. De Franco DJ, Spiller RE Jr, von Fraunhofer JA. 
Frictional resistances using Teflon-coated ligatures with various bracket-archwire combinations. Angle Orthod 1995;65:63-72; discussion 73-4.

24. Neumann P, Bourauel C, Jäger A. Corrosion and permanent fracture resistance of coated and conventional orthodontic wires. J Mater Sci Mater Med 2002;13:141-7.

25. Muguruma T, lijima M, Brantley WA, Nakagaki S, Endo K, Mizoguchi 1. Frictional and mechanical properties of diamond-like carbon-coated orthodontic brackets. Eur J Orthod 2013;35:216-22.

26. Bandeira AM, dos Santos MP, Pulitini G, Elias CN, da Costa MF. Influence of thermal or chemical degradation on the frictional force of an experimental coated NiTi wire. Angle Orthod 2011;81:484-9.

27. Mattox DM. Handbook of physical vapor deposition (PVD) processing. 2nd ed. Burlington: Elsevier; 2010.

28. Zuo J, Keil P, Grundmeier G. Synthesis and characterization of photochromic Ag-embedded $\mathrm{TiO}_{2}$ nanocomposite thin films by non-reactive RF-magnetron sputter deposition. Appl Surf Sci 2012;258: 7231-7.

29. Kuo CG, Hsu CY, Wang SS, Wen DC. Photocatalytic characteristics of $\mathrm{TiO}_{2}$ films deposited by magnetron sputtering on polycarbonate at room temperature. Appl Surf Sci 2012;258:6952-7.

30. Abraham KS, Jagdish N, Kailasam V, Padmanabhan S. Streptococcus mutans adhesion on nickel titanium (NiTi) and copper-NiTi archwires: a comparative prospective clinical study. Angle Orthod 2017;87:44854.

31. Cao B, Wang Y, Li N, Liu B, Zhang Y. Preparation of an orthodontic bracket coated with an nitrogendoped $\mathrm{TiO}_{2-}{ }_{x} \mathrm{~N}_{\mathrm{y}}$ thin film and examination of its antimicrobial performance. Dent Mater J 2013;32: 311-6.

32. Park JB, Kim YK. Metallic biomaterials. In: Bronzino JD, ed. The biomedical engineering handbook. 2nd ed. Boca Raton: CRC Press; 2000.

33. Rahmati M, Mozafari M. Biocompatibility of alumina-based biomaterials-a review. J Cell Physiol 2019; 234:3321-35.

34. Kao CT, Ding SJ, Chen YC, Huang TH. The anticorrosion ability of titanium nitride (TiN) plating on an orthodontic metal bracket and its biocompatibility. J Biomed Mater Res 2002;63:786-92.

35. Chung KH, Liu GT, Duh JG, Wang JH. Biocompatibility of a titanium-aluminum nitride film coating on a dental alloy. Surf Coat Technol 2004;188189:745-9.
36. Rahman SU, Ogwu AA. Corrosion and Mott-Schottky probe of chromium nitride coatings exposed to saline solution for engineering and biomedical applications. In: Ahmed W, Phoenix DA, Jackson MJ, Charalambous CP, eds. Advances in medical and surgical engineering. London: Academic Press; 2020. p. 239-65.

37. Pappas MJ, Makris G, Buechel FF. Titanium nitride ceramic film against polyethylene. A 48 million cycle wear test. Clin Orthop Relat Res 1995;(317):64-70.

38. Gil FJ, Solano E, Campos A, Boccio F, Sáez l, Alfonso MV, et al. Improvement of the friction behaviour of NiTi orthodontic archwires by nitrogen diffusion. Biomed Mater Eng 1998;8:335-42.

39. Kao CT, Guo JU, Huang TH. Comparison of friction force between corroded and noncorroded titanium nitride plating of metal brackets. Am J Orthod Dentofacial Orthop 2011;139:594-600.

40. Xu JL, Liu F, Wang FP, Yu DZ, Zhao LC. The corrosion resistance behavior of $\mathrm{Al}_{2} \mathrm{O}_{3}$ coating prepared on NiTi alloy by micro-arc oxidation. J Alloy Compd 2009;472:276-80.

41. Liu F, Shimizu T, Yue Q, Xu J, Wang F. Structure and tribological properties of micro-arc oxidation coatings for reduction of $\mathrm{Ni}^{2+}$ ion release on biomedical NiTi alloy. J Ceram Soc Jpn 2010;118:357-61.

42. Jagielski J, Khanna AS, Kucinski J, Mishra DS, Racolta P, Sioshansi P, et al. Effect of chromium nitride coating on the corrosion and wear resistance of stainless steel. Appl Surf Sci 2000;156:47-64.

43. Drescher D, Bourauel C, Schumacher HA. Frictional forces between bracket and arch wire. Am J Orthod Dentofacial Orthop 1989;96:397-404.

44. Ganss C, Schlueter N, Preiss S, Klimek J. Tooth brushing habits in uninstructed adults--frequency, technique, duration and force. Clin Oral Investig 2009;13:203-8.

45. Downing A, McCabe JF, Gordon PH. The effect of artificial saliva on the frictional forces between orthodontic brackets and archwires. Br J Orthod 1995; 22:41-6.

46. Pratten DH, Popli K, Germane N, Gunsolley JC. Frictional resistance of ceramic and stainless steel orthodontic brackets. Am J Orthod Dentofacial Orthop 1990;98:398-403.

47. Stannard JG, Gau JM, Hanna MA. Comparative friction of orthodontic wires under dry and wet conditions. Am J Orthod 1986;89:485-91.

48. Kusy RP, Whitley JQ. Influence of fluid media on the frictional coefficients in orthodontic sliding. Semin Orthod 2003;9:281-9. 